\title{
Examining the rights of children with intellectual disability in South Africa: Children's perspectives
}

\author{
Dana K. Donohue ${ }^{1}$ \\ Juan Bornman ${ }^{1}$ \\ Mats Granlund ${ }^{2}$ \\ Centre for Augmentative and Alternative Communication \\ University of Pretoria $^{1}$ \\ Jönköping University ${ }^{2}$
}

\begin{abstract}
Background. Human rights provide fundamental conditions for people to maintain dignity and selfdetermination and protect a nation's most vulnerable citizens. In South Africa, children with intellectual disability who experience socioeconomic disadvantage may be particularly vulnerable due to their cognitive impairments and inability to garner needed resources.

Method. The perceptions of children with intellectual disability regarding their access to basic amenities in their home environments were examined to determine whether their positive human rights were met. Risk factors were examined in relation to these perceptions.

$\underline{\text { Results. }}$ The results suggested that participants generally reported high degrees of access to basic resources. Logistic regressions suggested socioeconomic risk factors (e.g., income, education, household size, relationship status) were negatively related to children's reports of access to food and their own beds and positively related to having someone available to explain confusing concepts to them.

Conclusions. The positive human rights of children living in high risk environments should be monitored to ensure all South Africans have their rights met.
\end{abstract}




\section{Introduction}

Since the end of Apartheid in 1994, human rights are a reoccurring topic in South Africa. Ratified in 1996, the South African Bill of Rights ensures human rights and confirms the country's commitment to dignity and equality for its citizens. Almost two decades after the end of Apartheid, however, many South Africans still live in extreme poverty and there is substantial income inequality (McGrath \& Akoojee, 2007). With these economic realities in mind, a relevant question is, "are the human rights of all South Africans being met"?

Human rights are fundamental conditions for people to maintain dignity and freedom (Ruck, Keating, Abramovitch, \& Koegl, 1998) and often protect a country's most vulnerable citizens. Distinctions have been made between positive and negative human rights; positive rights confer the right to be provided with something such as food and housing, while the right not to experience an action (e.g., violence) is defined as negative rights. Whereas negative rights are subject to enforcement and redress, positive rights are more often subject to progressive realisation over time. Progressive realisation means that economic constraints may prevent all individuals from obtaining positive rights in the short term, but states must progressively make efforts to assist their citizens realise these rights (United Nations, 1966).

The United Nations has maintained the distinctions between positive and negative human rights with the development of two related covenants: the International Covenant on Economic, Social, and Cultural Rights (ICESCR; United Nations, 1966) which ensures individuals' positive human rights, and the International Covenant on Civil and Political Rights (ICCPR; United Nations, 1966), which ensures individuals' negative human rights. While South Africa is a signatory to both covenants and ratified the ICCPR in 1998, it has only approved the ratification of the ICESCR in 2012. Many of the positive rights within the ICESCR are mandated through the South African Bill of Rights (Republic of South Africa (RSA), 1996). For example, article 26 of the Bill of Rights ensures all South African citizens adequate housing, and article 27 ensures health care, water, food, and social 
security. Both articles 26 and 27 include provisions concerning the "progressive realisation of these rights" (RSA, 1996; p. 1255), similar to the ICESCR.

Human rights concerns are salient for the most vulnerable individuals in a population. Impoverished families' needs often are not met because they lack the means to obtain resources. Underdeveloped rural areas in South Africa frequently do not have clean water, electricity, and lack indoor plumbing, requiring residents to share community toilets (Nelson Mandela Foundation, 2005). When children grow up in these communities, they are exposed to a variety of daily risks, which can encumber the fulfilment of their rights.

Impoverished children often experience simultaneous multiple risks which increases their vulnerability (Alant \& Lloyd, 2005). Rutter's (1987) seminal research found that the accumulation of risks increased the likelihood of adverse developmental outcomes. Subsequent research found similar negative trends between risk and children's outcomes in academic achievement (Burchinal, Roberts, Zeisel, \& Rowley, 2008), language (Shonkoff \& Phillips, 2000), and IQ scores (Sameroff, Seifer, Zax, \& Barocas, 1987). Together, these findings suggest that, rather than the influence of a particular risk, the number of risks children were experiencing best predicted their outcomes.

In South Africa, children with disabilities arguably are one of the nation's most vulnerable populations because their age and impairments make them particularly dependent on others (Oosterhorn \& Kendrick, 2006). Poverty and mild intellectual disability are consistently linked (American Association of Intellectual and Developmental Disabilities \{AAIDD \}, 2010; Emerson, 2007), because poverty and its associated risk factors prevent many children from realising their cognitive potential (Grantham-McGregor et al., 2007). Intellectual disability occurs when a person experiences significant limitations in intellectual functioning and adaptive behaviours before 18 years of age (AAIDD, 2010). Between 80 and $90 \%$ of children with intellectual disability have a mild impairment (AAIDD, 2010). In South Africa, Christianson and colleagues (2002) conducted a 
prevalence study using neuro-developmental assessments and found that 29.1 per 1000 of the population had a mild intellectual disability, $73 \%$ of whom had undetermined aetiologies.

In the present context, a risk is any factor that predisposes children to negative developmental outcomes (Burchinal et al., 2008). Experiencing intellectual disability can be considered as one risk factor in relation to human rights that, in combination with environmental risk factors, negatively impacts on children's access to resources. The purpose of this research was to examine how risk factors related to the positive human rights of children with intellectual disability in South Africa.

\section{Socioeconomic risk factors in South Africa}

The United Nations Convention on the Rights of Persons with Disabilities (UNCRPD, 2006) estimates that $80 \%$ of all people with disabilities live in developing countries. This is due to the impoverished conditions in which many poor people live, which increase the likelihood of congenital or acquired disability. Many South Africans live in poverty due, in part, to the legacy of Apartheid policies along with high unemployment rates (Özler, 2007), preventing many caregivers from finding jobs to support their families.

Poverty is associated with inadequate nutrition and stunting of growth as well as lower maternal education, lower familial income, and home environments that are less conducive to child development (Grantham-McGregor et al., 2007). Poverty also creates stressors that stymie the creation of strong emotional bonds between caregivers, hindering shared parenting and emotional support that promotes effective care giving (Bradley, Whiteside, Mundfrom, Casey, Kelleher, \& Pope, 1994). The caregivers of children with disabilities generally are more stressed than those caring for a typically developing child (Montes \& Halterman, 2007). This is associated with their children's additional healthcare expenses (Järbrink, Fombonne, \& Knapp, 2003), and the stigma of disability in some communities (Shin, Nhan, Crittenden, Hong, Flory, \& Ladinsky 2006). Thus, impoverished children with intellectual disability may be more vulnerable when compared to their peers from more economically advantaged families. 
In this research, family income, caregiver relationship status, caregiver education, and household size were considered as socioeconomic risk factors. Low family income is related to insufficient resources for the provision of optimal developmental conditions for children in South Africa (Nelson Mandela Foundation, 2005), and particularly challenges caregivers of children with disabilities who experience additional healthcare needs (Järbrink et al., 2003) and those who are single parents. Less educated caregivers generally are less empowered and knowledgeable about best care practices for children with disabilities (Casey, Call, \& Klinger, 2001), and household crowding is associated with fewer caregiver-child interactions and poorer child development outcomes (Bradley et al., 1994).

\section{Other Potential Risk Factors in South Africa}

Gender. Many South Africans exhibit a male-dominant mindset and inequities remain despite the right to equal treatment under South African law (i.e., RSA, 1996; article 9, p. 1247). Many South Africans deem that men's roles are in the workforce, whereas women's positions are within the home (Department of Education, 1995). Jewkes and Abrahams (2002) stated that there remain “...dominant social constructions of masculinity in South Africa," (p. 1238). Females often are viewed as lacking autonomy and needing men for protection (Department of Education, 1995). When resources are scarce, girls are more likely to be deprived of basic necessities than boys (Nelson Mandela Foundation, 2005), suggesting that monitoring the rights of impoverished females may be appropriate in post-Apartheid South Africa.

Access to medical care. Children's access to quality medical care also influences their developmental outcomes, particularly children with disabilities who have additional medical needs. Children from low income families often have parents with relatively little education and therefore are unaware of how medical care can promote child wellness (Casey et al., 2001). Although free medical care is government policy for all South African children 0-9 years of age, many disempowered parents lack the knowledge or ability to access services. Together, these factors can lead to minimal utilization 
of medical services for children with disabilities, potentially contributing to lifelong detrimental effects (Waterston \& Goldhagen, 2007).

\section{Current study}

The current research forms part of a larger project that examined parental and child perspectives concerning the rights of children with intellectual disability in South Africa. Due to progressive realisation and economic constraints, positive human rights may be unmet for some children, particularly those in high risk environments. This exploratory study examined how socioeconomic and other risk factors were associated with the positive human rights of children with intellectual disability, from children's perspectives.

\section{Method}

Ethical clearance for conducting this study was obtained from the University of Pretoria. Formal permission also was obtained from the appropriate Provincial Departments of Education, school principals, teachers, and the children's primary caregivers.

\section{Participants}

A multi-phase sampling procedure was used for this research. First, province was sampled, followed by schools, and then children.

Provinces. Using per capita income as the representative aspect of province, three of the nine provinces in South Africa were purposively sampled for inclusion in this research. In terms of average annual income, Gauteng has the highest (approximately USD\$9,681), whereas KwaZulu Natal (approximately USD\$4,767) and Limpopo (approximately USD\$4,259) have two of the lowest average annual incomes per capita.

Schools. Following selection of provinces, school districts were identified using the National List of Special Schools (RSA, 2010). Districts containing government-funded special schools that provided services to children with intellectual disability were identified for potential inclusion. Thirteen school districts in Gauteng, 12 in KwaZulu Natal, and five in Limpopo met these criteria. To 
maintain comparable ratios between districts within provinces, two school districts in Gauteng (Tshwane South and Ekurhuleni North), two school districts in KwaZulu Natal (Umlazi and Ilembe), and one in Limpopo (Mopani) were randomly selected for potential participation.

Within Gauteng, principals of five of the six schools in the Tshwane South district provided consent, whereas two of three principals consented in the Ekurhuleni North district, for a total of seven schools in Gauteng that consented to participation. Of these seven schools, two used English as the language of instruction and five used Afrikaans. Within KwaZulu Natal, two of the five principals contacted provided consent within the Umlazi district, and the one principal from the Ilembe district consented, for a total of three schools in KwaZulu Natal (language of instruction for all was isiZulu). The principal from one of the possible two schools in the Mopani district of Limpopo provided consent (language was Xitsonga). Thus, a total of 11 schools provided consent to participate in this research. Reasons for not consenting included time constraints or adhering to internal policies of not allowing researchers into the school during school hours.

Children. Principals were asked to identify classrooms in which children with intellectual disability (without co-morbid sensory impairments) between eight and 14 years of age were taught. All teachers were given a standard set of instructions to identify children in their classroom who were between eight and 14 years of age and experienced no hearing loss or uncorrected sight problems for potential participation. Consent forms were sent home to the caregivers of children who were identified. The consent forms were provided to caregivers in the language of instruction at the children's school and were evaluated by two adults fluent in the target language to ensure they would be readable by caregivers with at least a high school education. Children returned the consent forms to the classroom teachers, and the researchers collected them.

A total of 234 children received consent from their caregivers, but two children declined to participate. To determine whether the remaining 232 children could respond appropriately to the questions, they were presented with both training and trial items for the questionnaire. Three training 
items were provided to acquaint participants with the Talking Mats ${ }^{\mathrm{TM}}$ (Murphy, 1998) procedure in terms of the questionnaire, concepts, and symbols. Three trial items subsequently were given. If the children failed to respond appropriately to two of the three trial items, the questionnaire administration was discontinued.

Twelve children failed the trial items and were thus determined unable to complete the research procedure. Child data were collected from 220 participants. For this particular research, demographic data from the caregiver questionnaire was essential for the creation of the socioeconomic risk index. Because of this, data were only used for children not living in group homes and whose primary caregivers completed the demographic questionnaire in order to ensure that the socioeconomic information used for the risk index was an accurate representation of the children's home environments. This resulted in an additional 32 participants being dropped from the analyses. Statistical comparisons revealed that those 32 participants did not differ significantly from the remaining participants on access to (equal variances assumed): water $t(218)=-.63, p=.53$; food $t(218)=.44, p=.66$; medicine $t(218)=.19, p=.85$; play $t(218)=.54, p=.59$; care $t(218)=-.20, p=$ .85 ; and (equal variances not assumed) bed $t(64.13)=-1.77, p=.08$. A statistically significant difference was found (equal variances not assumed) for someone to provide explanations $t(58.12)=$ $2.41, p=.02$, with the non-included data evidencing a higher mean score $(M=3.52, S D=.76)$ than the included data $(M=3.13, S D=1.15)$. Also, having friends with whom to play $t(102.93)=-3.19, p=$ .00 , was significantly different with the excluded participant data evidencing a higher mean score $(M=$ $3.81, S D=.40)$ than the included participant data $(M=3.51, S D=.94)$. Of the remaining 188 participants, 27 were found to be missing data on at least one relevant variable in the analyses. Results of Little's MCAR test indicated the data were missing completely at random $\chi 2(109)=113.47, p=.37$ and they subsequently were deleted. The final sample was 161 children. Participants were predominately male $(n=110)$ and their median age was 11 years old. Most had access to medical care $(n=131)$. Participant descriptives are found in Table 1. 


\section{Materials}

The materials used for this study were provided in Afrikaans, English, Xitsonga, or isiZulu. All measures were initially designed in English. The translation of the materials was conducted using a blind back-translation process (Bornman, Sevcik, Romski \& Pae, 2010). A translator provided a word-for-word translation from the source language to the target language and a second person translated it back from the target language to the source language. The back-translated version then was compared to the original version. If discrepancies between the materials were found, they were discussed until a final version was devised.

Child's Rights Questionnaire (CRQ). Questionnaire items were created based on the positive human rights found in the United Nations Convention on the Rights of the Child (UNCRC, 1989) and several articles within the South African Bill of Rights (RSA, 1996). The questionnaire was designed to obtain the perspectives of children with intellectual disability living in South Africa as to whether their human rights were met. The questionnaire development was based on UNCRC article 23 (i.e., children with disabilities should have a decent life, accessibility to needed resources, healthcare, education, rehabilitation services). The corresponding articles in the Bill of Rights were article 9: Equality; article 26: Housing; article 27: Healthcare, food, and water; and article 28: Children (right to care, protection, nutrition, shelter).

Items on the questionnaire were devised by a group of four graduate students who were working on this research project to complete their graduate theses. The items they developed were also suggested as areas to be addressed when examining the rights of children with disabilities in an international context (by Simmeonsson \& Granlund, 2011). After the items were devised, they were provided to an expert panel of four disability professionals in South Africa. The experts suggested several alterations to the wording of the questions. For example, the item, Do you have water to drink? was changed to, Do you have clean water to drink at home? in order to highlight the specific need (i.e., clean water) and the context (i.e., at home). Additionally, Do you have a place to sleep? 
was changed to Do you have your own bed to sleep in at home? because all children would have a place to sleep, but not all children may have their own bed. Other suggested alterations included things - rather than toys - with which to play because of the potential cultural differences with the interpretation of the concept of toys, as well as the addition of medicine when you are sick because many participants may not have needed medicine on a daily basis. The item Do you like it when people get angry with you? was added to the questionnaire to determine whether participants were responding with acquiescence bias. The items on the final questionnaire addressed access to clean water, food, medicine, beds, things for play, care, someone who explained things, and friends.

A 4-point rating scale was utilised, with a score of 1 representing "never," 2 representing "seldom," 3 representing "sometimes," and a score of 4 representing "always." The questionnaire completed by the children used the Talking Mats ${ }^{\mathrm{TM}}$ (Murphy, 1998) format, which provides children with visual depictions of the items in order to decrease the potential confounding effects of memory deficits and/or language production. Each item on the questionnaire was read aloud and a Picture Communication Symbol (PCS ${ }^{\mathrm{TM}}$; Mayer-Johnson, 1992) was presented that visually depicted that item. The children were asked how much they had access to each of the items.

In order to test the format and procedures, two pilot studies were conducted. The first pilot was undertaken with five typically developing children between seven and nine years of age. The results suggested that the terminology and procedure were appropriate, but the Likert scale needed to be repeated following every new item. A scripted routine also was recommended to ensure procedural integrity. The second pilot study included ten children with intellectual disability who did not participate in the main study, between nine and 13 years of age. No further alterations were recommended.

Demographic questionnaire. Primary caregivers independently completed a questionnaire provided in the language of instruction at their children's schools (see Table 1). Items asked about income, education, household size, and relationship status. Some items related to the child also were 
included (e.g., access to medical care and gender). Caregivers were also asked about their children's access to home amenities (e.g., Does your child have food to eat at home?). While caregiver responses and their association to child responses will be the focus of future manuscripts, they are briefly discussed below in terms of inter-rater reliability with the children's responses.

Risk index. A risk index was created using items from the caregiver questionnaire: income, education, household size, and relationship status. Participants received a point for every high risk socioeconomic factor they were experiencing: 1) if their annual familial income was less than R60,000 (approximately USD\$7,500); 2) if their primary caregivers' highest education was grade 10 or below; 3) if they lived in a household with seven or more people; and 4) if the caregivers were not married nor in a steady relationship. Participants' scores on the risk index ranged from $0-4$. The frequencies are displayed in Table 1.

\section{Procedure}

A packet was sent home to the primary caregivers of potential participants with a consent form explaining the purpose of the study. If they agreed to their child's participation, they signed the consent form, completed the biographical questionnaire, and returned the materials to the school. The children for whom parental consent was obtained were brought individually to a quiet testing place. In accordance with guidelines for obtaining assent by the Society for Research in Child Development (2003), interviewers who were fluent in the language of instruction at the schools explained the study's purpose, told the children that everything they said would be confidential, and that they could choose whether they wanted to participate. For those who assented, the questionnaire was administered during individual sessions of approximately 20 minutes per participant.

\section{Data analysis}

Data were analysed with SPSS 20.0. First, reliability estimates were computed for the CRQ. Then, means, standard deviations, and frequencies were computed for the CRQ. Because the data were 
negatively skewed, they were dichotomised into low (1-3) or high scores (4). Logistic regressions were used to determine the influence of the predictors on CRQ scores.

\section{Reliability estimates}

Inter-rater reliability scores were computed to investigate the agreement between children's responses with caregiver responses on the same items. Due to the negatively skewed distributions for both the children and their caregivers, Cohen's kappa was not used for calculations. Instead, the proportion of exact agreements of child-caregiver pairs was calculated. The proportion of exact agreements varied from $82.7 \%$ agreement on items related to basic physiological needs such as clean water to drink to a low of $51.2 \%$ for the item Do you have friends to play with at home?. Overall agreement was higher for more basic observable amenities, such as food and water, than for those items related more to perceptions (e.g., friends). Internal consistency reliability scores of the CRQ were then examined using Cronbach alpha scores. The overall score was low, with $\alpha=.49$. The one item that was found to suppress reliability scores, Do you have friends to play with at home?, was deleted from the scale, which increased reliability to $\alpha=.53$.

\section{Results}

\section{Child's Rights Questionnaire}

The descriptive data for the CRQ are provided in Table 2. It should firstly be noted that all items evidenced means above 3 , suggesting that participants generally reported that the positive human rights measured here were met. Participants reported high access to food $(M=3.86, S D=.38)$, clean water $(M=3.82, S D=.45)$, and someone who cared for and protected them $(M=3.80, S D=.50)$, with little variability in participants' responses. With relatively lower means, participants reported they had their own bed $(M=3.47, S D=1.06)$ and medicine $(M=3.40, S D=.89)$. Participants were least likely to report access to someone who explained things $(M=3.13, S D=1.15)$ and things with which to play $(M=3.19, S D=1.16)$. 


\section{Logistic regression analyses}

After the scores were dichotomised, logistic regressions were run. Because these data were collected in the school context, school effects were controlled by entering school-level data into the first step of sequential logistic regression models. Some of the parameter estimates from the initial analyses were extremely large, suggesting too few cases compared to predictors and that some of the predictors should be collapsed (Tabachnick \& Fidell, 2007). Composite variables for the schools in each province were therefore created.

\section{Clean water}

The full model was not statistically significant, $\chi 2(5)=10.46, p=.06$ and Nagelkerke's pseudo

$R^{2}=.11$ was moderate. Together, these statistics suggested that, compared to a constant-only model, the full model modestly distinguished between children with low and high scores on their access to clean water. None of the parameters were statistically significant and a score of 1.00 fell between the 95\% confidence intervals for the odds ratios of each predictor, which indicated that changes in the values of the predictors were not significantly associated with children's scores on the water item.

\section{Food}

The full model was not statistically significant, $\chi 2(5)=9.17, p=.10$ and Nagelkerke's pseudo $R^{2}=.10$ was modest. According to the Wald criterion, the risk index was a statistically significant predictor of participants' food scores, $\chi 2(1, N=161)=4.18, p<.05$. The odds ratio indicated that each increase in the risk index decreased the odds of reporting high scores on the food item by a factor of $.61(95 \% \mathrm{CI}=.38-.98)$. When inverted, the odds ratio suggested that for each one point increase on the risk index, participants were 1.64 times more likely to report low scores on the food item.

\section{Medicine}

The full model was statistically significant, $\chi 2(5)=14.12, p=.02$ and Nagelkerke's pseudo $R^{2}=$ .11 was moderate. None of the parameters were statistically significant and a score of 1.00 fell between the $95 \%$ confidence intervals for the odds ratios of each predictor. 


\section{Bed}

A test of the full model with the predictors against a constant-only model was statistically significant, $\chi 2(5)=12.79, p=.03$ and Nagelkerke's pseudo $R^{2}=.12$ was moderate. The risk index was a statistically significant predictor of whether children always had their own bed, $\chi 2(1, N=161)=$ $6.90, p<.05$, indicating that each point increase in the risk index decreased the odds of participants reporting they had their own bed by a factor of $.61(95 \% \mathrm{CI}=.42-.88)$. For each point increase of risk, participants were 1.64 times more likely to report low scores for access to their own bed.

Play

A test of the model against a constant-only model was non-significant, $\chi 2(5)=5.89, p=.32$ and Nagelkerke's pseudo $R^{2}=.10$ was moderate. None of the parameters were statistically significant and a score of 1.00 fell between the $95 \%$ confidence intervals for each of the odds ratios.

\section{Confused}

A test of the full model against a constant-only model was not statistically significant, $\chi 2(5)=$ $8.37, p=.14$ and Nagelkerke's pseudo $R^{2}=.07$ was small. Risk was a significant predictor of whether children had someone to explain things to them when they were confused, $\chi 2(1, N=161)=5.70, p<$ .05. For each point increase in the risk index, children were 1.44 times $(95 \% \mathrm{CI}=1.07-1.95)$ more likely to report that they had someone available to explain confusing concepts to them.

\section{Care and protection}

The full model was not statistically significant, $\chi 2(5)=8.15, p=.15$ and Nagelkerke's pseudo $R^{2}=.08$ was moderate. No parameters were statistically significant and a score of 1.00 fell between the $95 \%$ confidence intervals of the odds ratios.

\section{Discussion}

This exploratory study examined how socioeconomic and other risk factors were associated with the positive human rights of children with intellectual disability, from children's perspectives. A questionnaire based on articles in the UNCRC (1989) and corresponding articles in the South African 
Bill of Rights was developed and utilised for this aim. On average, participants reported that their positive human rights tapped by the CRQ were "sometimes" or "always" fulfilled. The mean scores revealed that participants reported the highest degree of access to food and water, and the lowest degree of access to having things with which to play and someone to explain concepts that confused them.

Several findings warrant discussion. First, the risk index evidenced a negative relationship with children's reports of access to food, where for each point increase on the risk index, participants were 1.64 times more likely to report low scores for their access to food. In other words, for every additional risk experienced, children were about one and a half times more likely to report that they did not always have food. Although South Africa has substantially improved the human condition over the past two decades, this finding is not altogether surprising. Many families remain in abject poverty and struggle everyday to meet their daily needs. Some caregivers report their children's only nutritious meal is eaten at school (Nelson Mandela Foundation, 2005). These findings emphasise that the country's most destitute communities should be monitored to ensure that, at the very least, the children living there obtain adequate caloric intake.

A negative effect also was found for access to beds, where for each additional socioeconomic risk, children were 1.64 times more likely to report that they did not always have their own beds in which to sleep. Co-sleeping is not an unusual phenomenon in some cultures (Owens, 2004) and it may be normal for some children in South Africa to sleep in beds with their relatives. Yet, the results indicate that children living in higher risk conditions were significantly more likely to report that they did not always have their own bed. Thus, rather than a cultural explanation, these results suggest that co-sleeping may be related to families' financial constraints: poor families cannot afford the cost of individual beds or they might not have space for children to have their own beds.

A positive effect of risk was found for the item, Do you have someone to explain things to you when you are confused?, where a one point increase in the risk index was associated with children 
1.44 times more likely to report that they had someone available to explain confusing concepts to them. This finding was interesting because previous research found that African caregivers generally do not engage in extended conversations with children because it is viewed as inappropriate (Geiger \& Alant, 2005). However, Geiger and Alant's study was conducted with typically developing children and this research was concerned with children with intellectual disability. Future research could examine whether there are differences in the conversations between caregivers and their typically and atypically developing children to determine the source of the differences between these findings. In this research, the differences found between low and high risk children may suggest that some of these children were living in large households, with at least several older adults at home to help the children when they had questions. Their caregivers also may have been more likely to be unemployed, at home, and more available to talk to their children.

\section{Limitations}

There were several study limitations. Firstly, children were asked about their perceptions of their home environments; whether these perceptions reflect reality is uncertain. However, checks were in place (i.e., trial and training items, acquiescence bias question), to ensure that participants were at least capable of considering the items before answering.

Another limitation was the composition of the sample, where all the children sampled were attending school. Considering that up to $70 \%$ of children with disabilities in South Africa do not attend school (Department of Education, 2001), we likely have obtained responses from more fortunate children. This may also relate to why no meaningful effects were found for gender.

Children with more severe intellectual disability were not included in this project. The reasons for this were twofold: 1) children with severe impairments generally do not attend school in South Africa, and 2) we likely could not have used the same self-report methodology used here. We think an important follow-up study would examine the relationships between risks and rights for children with severe intellectual disability in South Africa, as they may be even more vulnerable than the cohort in 
the present study. Another limitation is that only participants whose primary caregivers completed the questionnaire and only participants not living in group homes were included.

A final limitation was the low internal consistency estimates of the CRQ. On the one hand, low internal consistency scores may indicate a high degree of measurement error (Hartmann \& Pelzel, 2005). On the other hand, low internal consistency estimates may simply reflect that the CRQ tapped a broad spectrum of rights and thus a high summary reliability score would not be expected.

\section{Conclusions}

Given the methodological limitations of the CRQ, the results of this research should be considered exploratory and future research should focus on improving the scale's psychometric properties. The results of this research suggested that South African children with intellectual disability generally reported high degrees of access to basic amenities in their home environments indicating that most had their positive human rights met. It was found, however, that risk influenced their access to resources. Children who lived in higher risk environments were more likely to report that they always had someone available to explain confusing concepts to them, while they were less likely to report that they always had food or their own bed. In consideration of these findings, we suggest that the positive human rights of children living in high risk environments are monitored to ensure that the basic needs of all South Africans are met.

\section{Acknowledgments}

We would like to express our sincere appreciation to our colleagues who assisted with data collection.

\section{Authors' Note}

This research was funded by the Swedish International Development Cooperation Agency (SIDA) grant number 70883. This funding body has no restrictions on free access or publication of this data. Additionally, the authors have no financial or non-financial conflicts of interest. 


\section{References}

Alant, E., \& Lloyd, L. (Eds) (2005). AAC and severe disabilities: Beyond Poverty. London: Whurr Publications.

American Association of Intellectual and Developmental Disabilities (AAIDD; 2010). Intellectual Disability: Definition, Classification and Systems of Support. Washington: AAIDD.

Bornman, J., Sevcik, R., Romski, M.A., \& Pae, H.K. (2010). Successfully translating language and culture when adapting assessment measures. Journal of Policy \& Practice in Intellectual Disabilities, 7(2), 111-118.

Bradley, R.H., Whiteside, L., Mundfrom, D.J., Casey, P.H., Kelleher, K.J., \& Pope, S.K. (1994). Early indications of resilience and their relation to experiences in the home environments of low birthweight, premature, children living in poverty. Child Development, 65, 346-360.

Burchinal, M.R., Roberts, J.E., Zeisel, S.A., \& Rowley, S.J. (2008). Social risk and protective factors for African American children's academic achievement and adjustment during the transition to middle school. Developmental Psychology, 44(1), 286-292.

Casey, M.M., Call, K.T., \& Klinger, J.M. (2001). Are rural residents less likely to obtain recommended preventive health care services? American Journal of Preventive Medicine, 21(3), 182-188.

Christianson, A.L., Zwane, M.E., Manga, P, Rosen, E., Venter, A., Downs, D., \& Kromberg, J.G.R. (2002). Children with intellectual disability in rural South Africa: prevalence and associated disability. Journal of Intellectual Disability Research, 46, 179 -186.

Department of Education (1995). White Paper on Education and Training in a Democratic South Africa: First steps to developing a new system. Pretoria: Government Printer. Department of Education (2001). White Paper 6: Building an inclusive education and 
training system. Pretoria: Government Printer.

Emerson, E. (2007). Poverty and people with intellectual disabilities. Mental Retardation/Developmental Disabilities Research Review, 13, 107-113.

Geiger, M., \& Alant, E. (2005). Child-rearing practices and children's communicative interactions in a village in Botswana. Early Years, 25(2), 183-191.

Grantham-McGregor, S., Cheung, Y.B., Cueto, P., Richter, L., Strupp, B., and the International Child Development Steering Group. (2007). Developmental potential in the first 5 years for children in developing countries. The Lancet, 369, $60-70$.

Hartmann, D.P., \& Pelzel, K.E. (2005). Design, measurement, and analysis in developmental research. In M. H. Bornstein and M. E. Lamb (Eds.) Developmental Science: An Advanced Textbook, $5^{\text {th }}$ ed. (pp. 103-186). Mahwah, NJ: Lawrence Erlbaum Associates, Inc.

Järbrink, K., Fombonne, E., \& Knapp, M. (2003). Measuring the parental, service and cost impacts of children with autistic spectrum disorder: a pilot study. Journal of Autism and Developmental Disorders, 33, 395-402.

Jewkes, R., \& Abrahams, N. (2002). The epidemiology of rape and sexual coercion in South Africa: An overview. Social Science \& Medicine, 55, 1231-1244.

Mayer-Johnson, R. (1992). The Picture Communication Symbols. Solana Beach, CA: Mayer-Johnson Co.

McGrath, S., \& Akoojee, S. (2007). Education and skills for development in South Africa: Reflections on the accelerated and shard growth initiative for South Africa. International Journal of Educational Development 27, 421-434.

Montes, G., \& Halterman, J.S. (2007). Psychological functioning and coping among mothers of children with autism: a population-based study. Pediatrics, 119(5), 
1040-1046.

Murphy, J. (1998) Talking Mats: speech and language research in practice. Speech and Language Therapy in Practice, Autumn, 11-14.

Nelson Mandela Foundation (2005). Emerging Voices: A Report on Education in South African Rural Communities. Pretoria: HSRC Press.

Oosterhorn, R., \& Kendrick, A. (2001). No sign of harm: Issues for disabled children communicating about abuse. Child Abuse Review, 10, 243-253.

Özler, B. (2007). Not separate, not equal: Poverty and inequality in post-apartheid South Africa. Economic Development and Cultural Change, 55(3), 487-529.

Republic of South Africa (1996). Constitution of the Republic of South Africa No. 108 of 1996. Retrieved October 1, 2012 from http://www.info.gov.za/documents/constitution/1996/a108-96.pdf.

Republic of South Africa (2010). National List of Special Schools. Retrieved October 18, 2012 from www.thutong.doe.gov.za/ResourceDownload.aspx?id=40391.

Ruck, M. D., Keating, D. P., Abramovitch, R., \& Koegl, C. (1998). The development of children's knowledge about rights: Some evidence for how young people view rights in their own lives. Journal of Adolescence, 21, 275-289.

Rutter, M. (1987). Psychosocial resilience and protective mechanisms. American Journal of Orthopsychiatry, 57(3), 316-331.

Sameroff, A.J., Seifer, R., Zax, M., Barocas, R.(1987). Early indicators of developmental risk: the Rochester longitudinal study. Schizophrenia Bulletin, 13, 383-94.

Shin, J., Nhan, N.V., Crittenden, K.S., Hong, H.T.D., Flory, H., \& Ladinsky, J. (2006). Parenting stress of mothers and fathers of young children with cognitive delays in Vietnam. Journal of Intellectual Disability Research, 50, 748-760. 
Shonkoff, J.P., \& Phillips, D.A., (Eds.) (2000). From Neurons to Neighborhoods: The Science of Early Childhood Development. Washington, DC: National Academic Press.

Simeonsson, R.J., \& Granlund, M. (2011, February). Human Rights and the ICF-CY in Poverty Contexts. Paper presented at the seminar: Using the ICF-CY for planning, implementing and evaluating benefits for children and families with disabilities in a poverty setting, Pretoria, South Africa.

Society for Research in Child Development (2003). Directory of members. Chicago: SRCD.

Tabachnick, B.G., \& Fidell, L.S. (2007). Using multivariate statistics, $5^{\text {th }}$ ed. Boston: Allyn and Bacon.

United Nations (1966). Yearbook of the United Nations 1966. New York: Columbia University Press/United Nations Publications.

United Nations (1989). United Nations Convention on the Rights of the Child. Office of the United Nations High Commissioner for Human Rights: Geneva.

United Nations (2006). United Nations Convention on the Rights of Persons with Disabilities. Office of the United Nations High Commissioner for Human Rights: Geneva.

Waterston, T., \& Goldhagen, J. (2007). Why children's rights are central to international child health. Archives of Disease in Childhood, 92(2), 176-180. 
Table 1.

Participant descriptives: Means, standard deviations, frequencies, and percentages $(N=161)$.

Child Descriptives

\begin{tabular}{|c|c|c|c|c|c|}
\hline Gender & $\begin{array}{c}\text { Male } \\
n=110 \\
68.3 \%\end{array}$ & $\begin{array}{l}\text { Female } \\
n=51 \\
31.7 \%\end{array}$ & & & \\
\hline Access to medical services? & $\begin{array}{c}\text { No } \\
n=30 \\
18.6 \%\end{array}$ & $\begin{array}{c}\text { Yes } \\
n=131 \\
81.4 \%\end{array}$ & & & \\
\hline Child age & $\begin{array}{l}\text { 96-172 months } \\
\text { of age }\end{array}$ & $\begin{array}{c}M=11 \text { years, } 5 \\
\text { months of age }\end{array}$ & $\begin{array}{c}S D=18.06 \\
\text { months of age }\end{array}$ & & \\
\hline Province & $\begin{array}{l}\text { Gauteng } \\
n=76 \\
47.2 \%\end{array}$ & $\begin{array}{c}\text { KwaZulu Natal } \\
n=48 \\
29.8 \%\end{array}$ & $\begin{array}{c}\text { Limpopo } \\
n=37 \\
23 \%\end{array}$ & & \\
\hline $\begin{array}{l}\text { School language of } \\
\text { instruction }\end{array}$ & $\begin{array}{c}\text { English } \\
n=38 \\
23.6 \%\end{array}$ & $\begin{array}{c}\text { Afrikaans } \\
n=38 \\
23.6 \%\end{array}$ & $\begin{array}{c}\text { Xitsonga } \\
n=37 \\
23 \%\end{array}$ & $\begin{array}{l}\text { isiZulu } \\
n=48 \\
29.8 \%\end{array}$ & \\
\hline $\begin{array}{l}\text { Home Environment } \\
\text { Descriptives }\end{array}$ & & & & & \\
\hline Primary caregiver age & $22-67$ years & $M=39.55$ & $S D=8.66$ & & \\
\hline Urban or rural dwelling? & $\begin{array}{l}\text { Urban } \\
n=76 \\
47.2 \%\end{array}$ & $\begin{array}{l}\text { Rural } \\
n=85 \\
52.8 \%\end{array}$ & & & \\
\hline Familial income per annum & $\begin{array}{c}\mathrm{R} 60,000 \text { or less } \\
n=104 \\
64.6 \%\end{array}$ & $\begin{array}{c}\text { Above } \mathrm{R} 60,000 \\
n=57 \\
35.4 \%\end{array}$ & & & \\
\hline $\begin{array}{l}\text { Highest education of primary } \\
\text { caregiver }\end{array}$ & $\begin{array}{c}\text { Grade } 10 \text { or } \\
\text { less } \\
n=76 \\
47.2 \%\end{array}$ & $\begin{array}{c}\text { Above grade } \\
10 \\
n=85 \\
52.8 \%\end{array}$ & & & \\
\hline $\begin{array}{l}\text { How many people live in } \\
\text { household }\end{array}$ & $\begin{array}{c}\text { Less than } 7 \\
\text { people } \\
n=129 \\
80.1 \%\end{array}$ & $\begin{array}{c}7 \text { people or } \\
\text { more } \\
n=32 \\
19.9 \%\end{array}$ & & & \\
\hline $\begin{array}{l}\text { Primary caregiver } \\
\text { relationship status }\end{array}$ & $\begin{array}{l}\text { Married } \\
n=83 \\
51.6 \%\end{array}$ & $\begin{array}{c}\text { Committed } \\
\text { partner } \\
n=19 \\
11.8 \%\end{array}$ & $\begin{array}{c}\text { Single parent } \\
\quad n=48 \\
29.8 \%\end{array}$ & $\begin{array}{c}\text { Widowed } \\
n=11 \\
6.9 \%\end{array}$ & \\
\hline Socioeconomic risk index & $\begin{array}{l}0 \text { risks } \\
n=32 \\
19.9 \%\end{array}$ & $\begin{array}{l}1 \text { risk } \\
n=32 \\
19.9 \%\end{array}$ & $\begin{array}{c}2 \text { risks } \\
n=58 \\
36 \%\end{array}$ & $\begin{array}{l}3 \text { risks } \\
n=33 \\
20.5 \%\end{array}$ & $\begin{array}{c}4 \text { risks } \\
n=6 \\
3.7 \%\end{array}$ \\
\hline
\end{tabular}


Table 2.

Means, standard deviations, frequencies, and internal consistency estimates for Child's Rights Questionnaire $(N=161)$.

\begin{tabular}{lccc}
\hline Item & Range & Mean & SD \\
\hline $\begin{array}{l}\text { Do you have clean water to drink at } \\
\text { home? }\end{array}$ & $1-4$ & 3.82 & .38 \\
$\begin{array}{l}\text { Do you have food to eat at home? } \\
\begin{array}{l}\text { Do you have medicine when you are } \\
\text { sick at home? }\end{array}\end{array}$ & $1-4$ & 3.86 & .89 \\
$\begin{array}{l}\text { Do you have your own bed to sleep in at } \\
\text { home? }\end{array}$ & $1-4$ & 3.40 & 1.06 \\
$\begin{array}{l}\text { Do you have things to play with at } \\
\text { home? }\end{array}$ & $1-4$ & 3.47 & .59 \\
$\begin{array}{l}\text { Do you like it when people get angry } \\
\text { with you? } \\
* * \text { acquiescence bias check** }\end{array}$ & $1-4$ & 3.19 & \\
$\begin{array}{l}\text { When you are confused, is there } \\
\text { someone to help explain things to you at } \\
\text { home? }\end{array}$ & $1-4$ & 1.25 & .50 \\
$\begin{array}{l}\text { Is there someone who cares for and } \\
\text { protects you at home? }\end{array}$ & $1-4$ & 3.13 & \\
\hline
\end{tabular}

